\title{
Terlipressin and albumin for type 1 hepatorenal syndrome: does bacterial infection affect the response?
}

\author{
Reskan Altun*, Murat Korkmaz, Emre Yıldırım, Serkan Öcal, Enver Akbaş and Haldun Selçuk
}

\begin{abstract}
Vasoconstrictor therapy with terlipressin and concomitant albumin can improve renal function in patients with hepatorenal syndrome (HRS) type 1, but the efficacy of therapy in patients with active infection is controversial. The aim of this study was to investigate the efficacy, adverse effects, and predictors of terlipressin therapy and to find out whether there was a difference in response rates between the patients with or without active infections. Data of 58 patients with type $1 \mathrm{HRS}$ treated with terlipressin and albumin were retrospectively evaluated. Twenty-six patients $(44.8 \%)$ showed complete response to treatment. Response rates of patients with or without active bacterial infection were 47 and $43.9 \%$, respectively $(p>0.05)$. Only baseline serum creatinine level was significantly related to response in univariate/multivariate analyses $(p<0.05)$. Twenty-three patients $(39.6 \%)$ developed adverse effects probably related to treatment. In $8.6 \%$ of patients, treatment was discontinued because of adverse effects of therapy. Four patients (6.9\%) developed ischemic adverse events, including nonfatal myocardial infarction, intestinal ischemia, and cutaneous necrosis. Terlipressin plus albumin therapy improved renal function in nearly half of patients with type 1 HRS. Thus, it seems a reasonable treatment for patients with active bacterial infections. Baseline serum creatinine level is a potential predictor of terlipressin response.
\end{abstract}

Keywords: Hepatorenal syndrome, Terlipressin, Albumin, Active bacterial infection

\section{Background}

Hepatorenal syndrome (HRS) is a potentially reversible, functional renal failure that occurs in patients with advanced liver disease. HRS is generally characterized by increased serum creatinine, azotemia, reduced diuresis, increased urine osmolarity, and reduced urine sodium values without signs of organic kidney damage (Salerno et al. 2007).

Vasoconstrictor therapy with terlipressin (a vasopressin-V1 receptor agonist), and concomitant albumin can improve renal function in patients with type 1 HRS (Ortega et al. 2002; Solanki et al. 2003; Martín-Llahi et al. 2008; Sanyal et al. 2008; Neri et al. 2008). Terlipressin seems to reverse the systemic and splanchnic vasodilatation, increase blood pressure, and decrease the

*Correspondence: reskanaltun@yahoo.com

Department of Gastroenterology, Baskent University, Ankara, Turkey hepatic-renal arterial resistance in cirrhotic patients with and without ascites (Narahara et al. 2009).

Many studies, including several randomized controlled trials, have shown that terlipressin is associated with a low incidence of adverse effects (Ortega et al. 2002; Solanki et al. 2003; Martín-Llahi et al. 2008; Sanyal et al. 2008; Neri et al. 2008; Moreau et al. 2002; Mulkay et al. 2001; Halimi et al. 2002). In the recent guidelines, a starting terlipressin dose of $0.5-1.0 \mathrm{mg} / 4-6 \mathrm{~h}$ by IV bolus has been recommended (Salerno et al. 2007). However, many unanswered questions remain regarding the optimal dose, optimal route of administration, and the potential adverse effects, including severe ischemic events.

According to the revised diagnostic criteria reported in 2007, patients with renal failure and active bacterial infections, without septic shock, are also considered as having HRS. Additionally, in the recent guidelines, starting the treatment of HRS before a complete recovery

\section{Springer}

(c) 2015 Altun et al. This article is distributed under the terms of the Creative Commons Attribution 4.0 International License (http://creativecommons.org/licenses/by/4.0/), which permits unrestricted use, distribution, and reproduction in any medium, provided you give appropriate credit to the original author(s) and the source, provide a link to the Creative Commons license, and indicate if changes were made. 
from the infection has been recommended (Salerno et al. 2007).

In this article, we have investigated a cohort of subjects with liver cirrhosis who fulfill the criteria of type 1 HRS according to the guidelines used at the time of diagnosis. The primary aim of this study was to investigate the efficacy, possible adverse effects, and potential predictors of terlipressin therapy. The secondary aim was to find out whether there was a difference in terms of complete response to treatment with terlipressin between the patients with or without active infections.

\section{Methods}

Data of 58 patients meeting the criteria of type 1 HRS, as proposed by the International Ascites Club at the time of diagnosis (Salerno et al. 2007; Arroyo et al. 1996), who underwent treatment with terlipressin at our hospital, were retrospectively reviewed. The protocol of this study was in accordance with ethical standards of Baskent University research committee and patients provided written informed consent to participate in the study.

All patients with suspected HRS were evaluated with the protocol that includes diuretic withdrawal, assessment of other possible causes of prerenal azotemia, and a trial of plasma expansion with albumin. To rule out renal parenchymal diseases, urine analyses and abdomen ultrasonography were performed. The presence of infection was evaluated with blood, sputum, urine, and ascitic fluid cultures as well as serum, and ascitic fluid leukocyte counts, serum C-reactive protein levels, and chest radiographs. In all patients, cultures were routinely obtained before the start of antibiotic therapy. Patients who fulfilled the criteria of type 1 HRS according to the guidelines used at the time of diagnosis were treated (Salerno et al. 2007; Arroyo et al. 1996). Thirty of 58 patients were diagnosed and managed based on previous criteria since the new criteria had yet to be published at that time. In 17 of the 28 patients diagnosed with the new criteria, an active bacterial infection was present. Ten of 17 patients had spontaneous bacterial peritonitis (presence of a polymorphonuclear leucocyte count $>250 / \mathrm{mm}^{3}$ in ascitic fluid, with or without positive culture). Other infections were as follows: three patients with bacterial pneumonia, three patients with urinary tract infection, and one patient with spontaneous bacteremia (presence of positive blood cultures without evident source of infection).

The exclusion criteria were as follows: presence of severe extrahepatic condition, including cardiovascular (coronary and/or peripheral arterial disease) and neurological diseases, septic shock, and hepatocellular carcinoma outside the Milan criteria.

All patients were hospitalized in the intensive care unit before therapy. Before therapy with terlipressin, all patients were monitored noninvasively. Arterial pressure and urinary output were checked every $4 \mathrm{~h}$. Cardiac rhythm was monitored continuously. An electrocardiogram was performed before and during treatment when needed. Patients with cardiac symptoms, and typical signs of ischemia on the first electrocardiogram were not included the study. All patients had an echocardiographic study within the 6 months period before treatment. Physical examination and routine laboratory tests were performed in all patients before the initiation of therapy and daily intervals during treatment.

During the first 3 days of treatment, terlipressin (glypressin $1 \mathrm{mg}$; Ferring GmbH, Kiel, Germany) was administered at a dose of $0.5-1 \mathrm{mg}$ every $4 \mathrm{~h}$ as an intravenous bolus in 50 patients and as a short-period infusion (15$30 \mathrm{~min}$ ) in eight patients. If after the first 3 days, serum creatinine decreased at least $25 \%$ of the pretreatment values, the dose remained unchanged. In patients whose serum creatinine did not decrease at least $25 \%$ of the pretreatment values within the first 3 days, the dose was increased up to a maximum of $2 \mathrm{mg} / 4 \mathrm{~h}$. Terlipressin was given until serum creatinine decreased below $1.5 \mathrm{mg} / \mathrm{dl}$ and urine output increased above $500 \mathrm{ml} /$ day. We did not use a fixed maximum time period for terlipressin treatment. Patients received $40 \mathrm{~g}$ of albumin during the first $24 \mathrm{~h}$, followed by $20 \mathrm{~g} /$ day. Patients with proven bacterial infection were treated with wide-spectrum antibiotics including second- and third-generation cephalosporins and carbapenems according to antimicrobial susceptibility. Prophylactic antibiotic therapy was not given during the treatment.

Severity of liver disease was assessed by the ChildPugh classification. Patients were followed until death, discharge, or liver transplantation. Patients developing recurrence were not evaluated again. Adverse effects of therapy were also recorded.

\section{Statistical analysis}

Results are presented as mean \pm standard deviation (SD) and median (minimum-maximum). Continuous variables were compared with Student's $t$ test, and MannWhitney test. Categorical variables were compared with Pearson Chi square and Fisher's exact tests. Univariate and multivariate logistic regression analyses were performed to identify predictors of response. A $p<0.05$ was considered as statistically significant. All analyses were done using the Statistical Package for the Social Sciences (SPSS) 19.0 (SPSS Inc. Chicago, IL, USA).

\section{Results}

Data of 58 patients with type 1 (HRS), who underwent treatment with terlipressin and albumin, were evaluated. Among 58 patients, $77.6 \%(n=45)$ and $22.4 \%(n=13)$ 
were men and women, respectively. Patients had a mean age of $52.6 \pm 10.6$ years. Cirrhosis was caused by viral hepatitis (28 patients with hepatitis B, 6 patients with delta hepatitis, and 2 patients with hepatitis $C)$ in $62.1 \%(n=36)$ of patients. Severity of cirrhosis defined by Child-Pugh score was Class A in $6.9 \%(n=4)$, Class B in $27.6 \%(n=16)$, and Class $C$ in $65.5 \%(n=38)$. Ascites was present in $87.9 \%$ $(n=51)$ of patients. Demographic and clinical characteristics of the patients before therapy are shown in Table 1.

Twenty-six patients $(44.8 \%)$ showed response to the treatment. Demographic and clinical characteristics of responders and nonresponders are summarized in Table 2. Of note, in 11 of 27 patients who did not show response to the treatment, the $24 \mathrm{~h}$ urine volume was increased over $500 \mathrm{ml} /$ day during treatment. Baseline serum creatinine was significantly low, and $24 \mathrm{~h}$ urine volume was significantly high in responders compared with nonresponders $(p<0.05)$.

Seventeen of the 58 patients $(29.3 \%)$ had an active bacterial infection, without septic shock. In the group of patients with HRS and active bacterial infection, 8 of 17 patients $(47 \%)$ showed response treatment with terlipressin and albumin, while 18 of 41 patients (43.9 \%) without active infection showed response $(p>0.05)$.

The variables, age, gender, etiology of cirrhosis, ChildPugh scores, existence of ascites, existence of active bacterial infection, serum total bilirubin, serum albumin, serum creatinine, serum sodium levels, $24 \mathrm{~h}$ urine volume, and mean arterial pressure (MAP) were evaluated as potential predictors of terlipressin and albumin response in both univariate and multivariate analyses (Table 3). Only baseline serum creatinine level $(<2.5 \mathrm{mg} /$ dl) was significantly related to response $(p<0.05)$.

Twenty-three patients (39.6\%) developed adverse effects probably related to the treatment, and in 5 of 58 patients

Table 1 Demographic and clinical characteristics of the 58 patients

\begin{tabular}{ll}
\hline Age $^{\text {a }}$ (years) & $52.6 \pm 10.6$ \\
Gender (M/F) & $45 / 13$ \\
Child-Pugh class (A/B/C) & $4 / 16 / 38$ \\
Etiology (viral hepatitis/others) & $36 / 22$ \\
Ascites ( \pm ) & $51 / 7$ \\
Active bacterial infection ( \pm ) & $17 / 41$ \\
Serum total bilirubin ${ }^{\mathrm{a}}(\mathrm{mg} / \mathrm{dl})$ & $2.8 \pm 0.8$ \\
Serum albumin $^{\mathrm{a}}(\mathrm{g} / \mathrm{dl})$ & $2.7 \pm 0.6$ \\
Serum creatinine $^{\mathrm{a}}(\mathrm{mg} / \mathrm{dl})$ & $2.2 \pm 0.8$ \\
Serum Na $^{\mathrm{a}}(\mathrm{mEq} / \mathrm{L})$ & $129 \pm 5$ \\
Urine volume $^{\mathrm{a}}(\mathrm{ml} /$ day) & $339 \pm 190$ \\
MAP $^{\mathrm{a}}(\mathrm{mmHg})$ & $78 \pm 9$
\end{tabular}

$M A P$ mean arterial pressure

${ }^{a}$ Mean \pm SD
Table 2 Demographic and clinical characteristics of responders and nonresponders before therapy

\begin{tabular}{|c|c|c|c|}
\hline & $\begin{array}{l}\text { Responders } \\
(n=26)\end{array}$ & $\begin{array}{l}\text { Nonresponders } \\
(n=27)\end{array}$ & $p$ \\
\hline Age (years) & $53.9 \pm 7.7$ & $53 \pm 11.4$ & NS \\
\hline Gender (M/F) & $19 / 7$ & $24 / 3$ & NS \\
\hline $\begin{array}{l}\text { Etiology of cirrhosis } \\
\text { (viral hepatitis/ } \\
\text { others) }\end{array}$ & $18 / 8$ & $16 / 11$ & NS \\
\hline $\begin{array}{l}\text { Child-Pugh class } \\
\text { (A/B/C) }\end{array}$ & $3 / 7 / 16$ & $1 / 7 / 19$ & NS \\
\hline Child-Pugh score & $9.8 \pm 2.5$ & $10.2 \pm 2$ & NS \\
\hline Ascites $( \pm)$ & $22 / 4$ & $25 / 2$ & NS \\
\hline $\begin{array}{l}\text { Active bacterial infec- } \\
\text { tion }( \pm)\end{array}$ & $8 / 18$ & $7 / 20$ & NS \\
\hline $\begin{array}{l}\text { Serum total bilirubin }{ }^{\mathrm{a}} \\
(\mathrm{mg} / \mathrm{dl})\end{array}$ & $2.6 \pm 0.8$ & $2.9 \pm 0.8$ & NS \\
\hline Serum albumin ${ }^{\mathrm{a}}(\mathrm{g} / \mathrm{dl})$ & $2.6 \pm 0.6$ & $2.7 \pm 0.5$ & NS \\
\hline $\begin{array}{l}\text { Serum creatinine }{ }^{a} \\
(\mathrm{mg} / \mathrm{dl})\end{array}$ & $1.9 \pm 0.4$ & $2.5 \pm 1$ & $<0.05$ \\
\hline Serum $\mathrm{Na}^{\mathrm{a}}(\mathrm{mEq} / \mathrm{L})$ & $129 \pm 6$ & $128 \pm 4$ & NS \\
\hline $\begin{array}{l}\text { Urine volume } \\
(\mathrm{ml} / \text { day })\end{array}$ & $400 \pm 186$ & $285 \pm 181$ & $<0.05$ \\
\hline $\mathrm{MAP}^{\mathrm{a}}(\mathrm{mmHg})$ & $80 \pm 10$ & $77 \pm 9$ & NS \\
\hline
\end{tabular}

NS nonsignificant, MAP mean arterial pressure

${ }^{a}$ Mean \pm SD

(8.6\%), treatment was discontinued because of treatmentemergent adverse effects. Sixteen patients $(27.6 \%)$ developed diarrhea, which subsided after cessation (1 patient), lowering dose (3 patients), or changing administration protocol to short-period infusion (12 patients) of terlipressin therapy. Three patients (5.2\%) developed abdominal pain, which subsided after changing administration protocol to short-period infusion (one patient) or lowering dose (two patients) of terlipressin therapy. Four patients (6.9\%) developed ischemic adverse events (myocardial infarction, intestinal ischemia, cutaneous necrosis). In one patient with cutaneous necrosis and two patients with intestinal ischemia, symptoms disappeared after terlipressin withdrawal. Finally, one patient developed nonfatal myocardial infarction during terlipressin therapy.

HRS recurred in $12(46.1 \%)$ of 26 patients who responded to treatment. Mean survival time was significantly greater in responders compared with nonresponders (42 \pm 6.2 and $21.8 \pm 4.3$ days, respectively, $p<0.05)$. Five patients had undergone transplantation. The transplant-free survival at 15 and 30 days of treatment was 54.7 and $32 \%$, respectively.

\section{Discussion}

Splanchnic vasodilation in cirrhotic patients may reduce effective arterial filling, resulting in renal vasoconstruction (Moller and Henriksen 2004). Intravascular volume 
Table 3 Univariate analysis for potential predictors of terlipressin and concomitant albumin response

\begin{tabular}{|c|c|c|}
\hline Variables & OR $(95 \% \mathrm{Cl})$ & $p$ \\
\hline \multicolumn{3}{|l|}{ Age } \\
\hline$>50$ & $2.0(0.67-5.98)$ & 0.21 \\
\hline \multicolumn{3}{|l|}{$\leq 50$} \\
\hline \multicolumn{3}{|l|}{ Gender } \\
\hline Male & $2.9(0.67-12.9)$ & 0.15 \\
\hline \multicolumn{3}{|l|}{ Female } \\
\hline \multicolumn{3}{|c|}{ Etiology of cirrhosis } \\
\hline Viral hepatitis & $1.5(0.49-4.80)$ & 0.45 \\
\hline \multicolumn{3}{|l|}{ Others } \\
\hline \multicolumn{3}{|c|}{ Child-Pugh score } \\
\hline$\leq 10$ & $1.7(0.57-5.05)$ & 0.33 \\
\hline \multicolumn{3}{|l|}{$>10$} \\
\hline \multicolumn{3}{|l|}{ Ascites } \\
\hline Yes & $2.2(0.37-13.63)$ & 0.36 \\
\hline \multicolumn{3}{|l|}{ No } \\
\hline \multicolumn{3}{|c|}{ Active bacterial infection } \\
\hline Yes & $1.2(0.38-4.20)$ & 0.69 \\
\hline \multicolumn{3}{|l|}{ No } \\
\hline \multicolumn{3}{|c|}{ Serum total bilirubin (mg/dl) } \\
\hline$\leq 3$ & $2.0(0.67-5.98)$ & 0.21 \\
\hline \multicolumn{3}{|l|}{$>3$} \\
\hline \multicolumn{3}{|c|}{ Serum albumin (g/dl) } \\
\hline$\geq 2.8$ & $1.51(0.49-4.57)$ & 0.46 \\
\hline \multicolumn{3}{|l|}{$<2.8$} \\
\hline \multicolumn{3}{|c|}{ Serum creatinine (mg/dl) } \\
\hline$<2.5$ & $6.13(1.47-25.44)$ & 0.01 \\
\hline \multicolumn{3}{|l|}{$\geq 2.5$} \\
\hline \multicolumn{3}{|c|}{ Serum $\mathrm{Na}(\mathrm{mEq} / \mathrm{L})$} \\
\hline$\geq 130$ & $2.45(0.76-7.88)$ & 0.13 \\
\hline \multicolumn{3}{|c|}{$<130$} \\
\hline \multicolumn{3}{|c|}{ Urine volume (ml/day) } \\
\hline$\geq 400$ & $2.33(0.76-7.08)$ & 0.13 \\
\hline \multicolumn{3}{|l|}{$<400$} \\
\hline \multicolumn{3}{|l|}{$\operatorname{MAPa}(\mathrm{mmHg})$} \\
\hline$\geq 80$ & $2.31(0.77-6.98)$ & 0.13 \\
\hline$<80$ & & \\
\hline
\end{tabular}

Cl confidence interval, $O R$ odds ratio

${ }^{a}$ MAP mean arterial pressure

expansion with vasoconstrictor drugs may reverse this vicious cycle and contribute to the treatment of patients with HRS or at risk of HRS (Krag et al. 2007). The achievement of optimal volume expansion is difficult in these patients with standard static hemodynamic measurements (Marik et al. 2008). Volume overload should be avoided owing to the risk of expanding third spaces and the subsequent development of abdominal compartment syndrome, which could reduce renal perfusion
(Dalfino et al. 2008). Studies have shown that the use of vasocontrictors, such as noradrenaline and terlipressin in conjunction with albumin, improves renal function in patients with HRS compared with the use of vasoconstrictors or albumin alone (Ortega et al. 2002; Solanki et al. 2003; Martín-Llahi et al. 2008; Sanyal et al. 2008; Neri et al. 2008; Sharma et al. 2008). Randomized controlled studies have shown that the HRS reversal rates achieved with terlipressin and albumin treatment ranged between 34 and 81 \% (Sanyal et al. 2008; Neri et al. 2008). The reason of this wide spectrum may be due to both complexity of the pathogenesis and difficulties in the assessment of effective treatment. In our study, similar to many randomized controlled trials (Solanki et al. 2003; Martín-Llahi et al. 2008), 44.8 \% of patients showed response to treatment.

According to the 2007 consensus report, patients with renal failure and active bacterial infections, without septic shock, are also diagnosed as having HRS. Additionally, starting the treatment before a complete recovery from the infection has been recommended (Salerno et al. 2007). The results of the study published by Barreto et al. in 2014 has supported this recommendation. They showed that type 1 HRS associated with infections is not reversible in two-thirds of patients with treatment of infection only (Barreto et al. 2014). This result has pointed to the terlipressin and albumin treatment again. The gap in the knowledge of type 1 HRS associated with infection has filled with the study of Rodriguez et al. Their study provides evidence indicating that terlipressin and albumin is also effective for the treatment of type 1 HRS associated with sepsis (Rodriguez et al. 2014).

In our study, we also compared groups of patients with or without active infection and found that there is no statistically significant difference between HRS reversal rates (47 and $43.9 \%$, respectively, $p>0.05$ ) as mentioned by Rodriguez et al. 2014. In many patients, type 1 HRS is triggered by bacterial infections given the aggravation of splanchnic vasodilatation by endotoxemia and cytokine overproduction (Arroyo et al. 2007). As shown in our study, it seems reasonable to treat these patients with terlipressin and albumin concomitantly with antibiotics.

Predictors of response to terlipressin and albumin therapy in patients with type 1 HRS in previous studies included baseline Child-Pugh and MELD scores, serum creatinine, serum bilirubin levels, $24 \mathrm{~h}$ urine volume, and the presence of an increase in MAP during therapy (Sanyal et al. 2008; Neri et al. 2008; Moreau et al. 2002; Boyer et al. 2011; Nazar et al. 2010). In our study, baseline serum creatinine was significantly low, and urine volume was significantly high in responders, whereas significant differences did not exist in terms of age, sex, serum bilirubin, serum albumin, serum sodium levels, 
and baseline MAP between responders and nonresponders. In a recent study (Boyer et al. 2011), it was reported that the most consistent predictor of response was baseline serum creatinine as observed in our study. Meanwhile, baseline serum creatinine was not associated with response in another study (Nazar et al. 2010). We think that predictors of response to terlipressin therapy are not well established in the literature, and further studies are needed.

Terlipressin has a low adverse effect profile comparing to other vasopressors that have been used for the treatment of HRS. However, it is recommended that terlipressin be used in an intensive care unit with close hemodynamic monitoring because of potentially serious ischemic adverse events (European association for the study of the liver 2010). In a randomized controlled trial including 112 patients with type 1 HRS, it was reported that serious adverse effects were mostly cardiovascular and were observed in $9 \%$ of patients treated with terlipressin and albumin. For this reason, in that study, treatment was discontinued in $5.4 \%$ of patients (Sanyal et al. 2008). In another randomized controlled trial, cardiovascular complications occurred in $22 \%$ of patients, but terlipressin therapy was discontinued in only one patient because of high blood pressure (Martín-Llahi et al. 2008). By comparison, a meta-analysis including 10 clinical trials, published before these two abovementioned trials reported that the pooled rate of withdrawal, and adverse effects of terlipressin therapy were 0 and $29 \%$, respectively. In our study, $39.6 \%$ of patients developed adverse effects related to treatment, and in $8.6 \%$ of patients, treatment was discontinued. These adverse effects were diarrhea (27.6\%), abdominal pain (5.2\%), and ischemic adverse events (6.9\%), including nonfatal myocardial infarction, intestinal ischemia, and cutaneous necrosis. Other adverse effects reported before, such as cardiac arrhythmias, hypertension, respiratory failure, and bronchospasm, were not observed. Further, none of our patients died because of terlipressin therapy.

In our study, adverse effects related to terlipressin therapy occurred after a mean of 2.6 days. Thus, it should be emphasized that close monitoring for adverse effects is required during the first few days of treatment, in particular, when treating patients with comorbidities.

Some authors suggest that continuous terlipressin infusion may have less severe adverse effects with the same response rates compared with intermittent IV bolus administration (Gerbes et al. 2009). However, this hypothesis has not been proven in any randomized, controlled trials yet. In our study, terlipressin was administered initially as an IV bolus in 50 patients, and as short-period infusion (15-30 $\mathrm{min}$ ) in eight patients. We did not compare the groups in terms of adverse effects because of the small number of patients. However, adverse effects subsided after changing the administration protocol from IV bolus to short-period infusion in $56.5 \%$ of patients who developed adverse effects. Thus, it should be noted that short-period infusion may be an alternative of IV bolus administration if the onset of adverse events occurs.

Our study has some limitations. First, it is a retrospective study with a relatively small number of patients. Moreover, predictive factors of response should be analyzed in a prospective study.

In conclusion, our study results indicate that terlipressin plus albumin therapy improves renal function in nearly half of patients with type 1 HRS. Further, it is reasonable to treat patients with type 1 HRS and active bacterial infections because of similar response rates compared with patients without active infections. Nevertheless, clinicians should be vigilant for severe adverse effects. We think that future studies should be focused on predictors of response to terlipressin therapy and therapies for prophylaxis as well as new pharmacological agents for nonresponders.

\section{Authors' contributions}

RA acquisition of data, analysis and interpretation of data, statistical analysis, drafting of manuscript. MK and HS critical revision of the manuscript for important intellectual content. EY acquisition of data and administrative. SÖ and EA administrative. All authors read and approved the final manuscript.

\section{Competing interests}

The authors declare that they have no competing interests.

\section{Ethical approval}

All procedures performed in this study were in accordance with ethical standards of Baskent University research committee and with the 1964 Helsink declaration and its later amendments or comparable ethical standards.

Funding

The authors declared that this study has received no financial support.

\section{Informed consent}

Informed consent was obtained from all individual participants included in the study.

Received: 20 September 2015 Accepted: 15 December 2015

Published online: 23 December 2015

\section{References}

Arroyo V, Gine`s P, Gerbes AL, Dudley FJ, Gentilini P, Laffi G et al (1996) Definition and diagnostic criteria of refractory ascites and hepatorenal syndrome in cirrhosis. International Ascites Club. Hepatology 23:164-176 Arroyo V, Terra C, Gines P (2007) Advances in the pathogenesis and treatment of type 1 and type 2 hepatorenal syndrome. J Hepatol 46:935-946 Barreto R, Fagundes C, Guevara M, Solà E, Pereira G, Rodríguez E et al (2014) Type 1 hepatorenal syndrome associated with infections in cirrhosis. Natural history, outcome of kidney function and survival. Hepatology 59:1505-1513

Boyer TD, Sanyal AJ, Garcia-Tsao G, Blei A, Carl D, Bexon AS et al (2011) Predictors of response to terlipressin plus albumin in hepatorenal syndrome type 1: relationship of serum creatinine to hemodynamics. J Hepatol 55:315-321 
Dalfino L, Tullo L, Donadio I, Malcangi V, Brienza N (2008) Intra-abdominal hypertension and acute renal failure in critically ill patients. Intensive Care Med 34:707-713

European Association for the Study of the Liver (2010) EASL clinical practice guidelines on the management of ascites, spontaneous bacterial peritonitis, and hepatorenal syndrome in cirrhosis. J Hepatol 53:397-417

Gerbes Al, Huber E, Gülberg V (2009) Terlipressin for hepatorenal syndrome: continuous infusion as an alternative to IV bolus administration. Gastroenterology 137:1179

Halimi C, Bonnard P, Bernard B, Mathurin P, Mofredj A, di Martino V et al (2002) Effect of terlipressin (glypressin) on hepatorenal syndrome in cirrhotic patients: results of a multicenter pilot study. Eur J Gastroenterol Hepatol $14: 153$

Krag A, Moller S, Henriksen JH, Holstein-Rathlou NH, Larsen FS, Bendtsen F (2007) Terlipressin improves renal function in patients with cirrhosis and ascites without hepatorenal syndrome. Hepatology 46:1863-1871

Marik PE, Baram M, Vahid B (2008) Does central venous pressure predict fluid responsiveness? A systematic review of the literature and the tale of seven mares. Chest 134:172-178

Martín-Llahi M, Pépin MN, Guevara M, Díaz F, Torre A, Monescillo A et al (2008) Terlipressin and albumin vs albumin in patients with cirrhosis and hepatorenal syndrome: a randomized study. Gastroenterology 134:1352-1359

Moller S, Henriksen JH (2004) Review article: pathogenesis and pathophysiology of hepatorenal syndrome- is there scope for prevention? Aliment Pharmacol Ther 20:31-41

Moreau R, Durand F, Poynard T, Duhamel C, Cervoni JP, Ichaï P et al (2002) Terlipressin in patients with cirrhosis and type I hepatorenal syndrome: a retrospective multicenter study. Gastroenterology 122(4):923-930

Mulkay JP, Louis H, Donckier V, Bourgeois N, Adler M, Deviere J et al (2001) Long-term terlipressin administration improves renal function in cirrhotic patients with type I hepatorenal syndrome: a pilot study. Acta Gastroenterol Belg 64:15
Narahara Y, Kanazawa H, Taki Y, Kimura Y, Atsukawa M, Katakura T et al (2009) Effects of terlipressin on systemic, hepatic and renal hemodynamics in patients with cirrhosis. J Gastroenterol Hepatol 24:1791-1797

Nazar A, Pereira GH, Guevara M, Martín-Llahi M, Pepin MN, Marinelli M et al (2010) Predictors of response to therapy with terlipressin and albumin in patients with cirrhosis and type 1 hepatorenal syndrome. Hepatology 51:219-226

Neri S, Pulvirenti D, Malaguarnera M, Cosimo BM, Bertino G, Ignaccolo L et al (2008) Terlipressin and albumin in patients with cirrhosis and type I hepatorenal syndrome. Dig Dis Sci 53:830-835

Ortega R, Gines P, Uriz J, Cárdenas A, Calahorra B, De Las Heras D et al (2002) Terlipressin therapy with and without albumin for patients with hepatorenal syndrome: results of a prospective, nonrandomized study. Hepatology 36:941-948

Rodriguez E, Elia C, Sola E, Barreto R, Graupera I, Andrealli A et al (2014) Terlipressin and albumin for type 1 hepatorenal syndrome associated with sepsis. J Hepatol 60:955-961

Salerno F, Gerbes A, Gines P, Wong F, Arroyo V. Diagnosis, prevention and treatment of the hepatorenal syndrome in cirrhosis. A consensus workshop of the international ascites club. Gut. 2007;56:1310-1318

Sanyal AJ, Boyer T, Garcia-Tsao G, Regenstein F, Rossaro L, Appenrodt B et al (2008) A randomized, prospective, double-blind, placebo-controlled trial of terlipressin for type 1 hepatorenal syndrome. Gastroenterology 134:1360-1368

Sharma P, Kumar A, Shrama PC, Sarin SK (2008) An open label, pilot, randomized controlled trial of noradrenaline versus terlipressin in the treatment of type 1 hepatorenal syndrome and predictors of response. Am J Gastroenterol 103:1689-1697

Solanki P, Chawla A, Garg R, Gupta R, Jain M, Sarin SK (2003) Beneficial effects of terlipressin in hepatorenal syndrome: a prospective, randomized placebo-controlled clinical trial. J Gastroenterol Hepatol 18:152-156

\section{Submit your manuscript to a SpringerOpen ${ }^{\circ}$ journal and benefit from:}

- Convenient online submission

- Rigorous peer review

- Immediate publication on acceptance

- Open access: articles freely available online

- High visibility within the field

- Retaining the copyright to your article

Submit your next manuscript at springeropen.com 